\title{
Giant Left Atrium in a case of Mitral stenosis with LA thrombus: A Case Report
}

\author{
Jubayer Ahmad, Md. Mokhlesur Rahman, Heemel Saha, Md. Aftabuddin, Asit Baran Adhikary \\ Department of Cardiac Surgery, Bangabandhu Sheikh Mujib Medical University, Dhaka
}

\author{
Key Words : \\ Giant left atrium, \\ Left atrial \\ thrombus, Mitral \\ valve \\ replacement, \\ atrial fibrilation.
}

\begin{abstract}
:
A 52 year-old male patient of severe MS with mild MR with AF with a giant left atrium (LA size 70 $\mathrm{mm}$ ) and history of CMC presented with symptoms. Giant left atrium is a condition characterized by huge enlargement of the left atrium with a diameter exceeding $65 \mathrm{~mm}$. It is most commonly associated with long standing rheumatic mitral valve disease. The patient underwent successful mitral valve replacement and removal of $L A$ thrombus and discharged from hospital with advice.
\end{abstract}

(Cardiovasc.j. 2016; 9(1): 73-74)

\section{Introduction:}

Giant left atrium (GLA) is commonly associated with long standing rheumatic mitral valve regurgitation or mixed mitral disease with predominant regurgitation. ${ }^{1}$ The exact etiology is not known. Both increased left atrial pressure and weakening of left atrial wall by rheumatic pancarditis are implicated in its development., The condition can be associated with atrial fibrilation, thromboembolic complications, hemodynamic and respiratory complications. ${ }^{3}$

Left atrial enlargement is a common feature of rheumatic mitral valve disease. Other causes of left atrial enlargement is left ventricular failure, chronic atrial fibrillation, and significant left to right shunts as seen in patent ductus arteriosus and ventricular septal defect. Giant left atrium is a feature of rheumatic valve disease with severe mitral regurgitation. ${ }^{4}$

We present a case of GLA with predominant mitral stenosis associated with atrial fibrilation and huge thrombus formation. The patient was successfully managed by mitral valve replacement and removal of LA thrombus.

\section{Case Report:}

A 52 years normotensive non diabetic old male was suffering from shortness of breath on exertion and palpitation for 3 months. The patient had history of ischaemic stroke with right sided weakness 16 years back. He had a successful closed mitral commissurotomy in 1998, since then he had been treated with digoxin and warfarin. Three months before admission his activity became limited due to increase shortness of breath and palpitation. Physical examination revealed he was anxious, right sided weakness with normal blood pressure and an irregular pulse. Cardiovascular examination revealed there was a curvilinear scar mark extending from lateral border of sternum to left mid axillary line over $4^{\text {th }}$ intercostal space, visible apex beat present in normal position, apical impulse in normal position, tapping in nature, a diastolic thrill present in mitral area. P2 palpable, loud $1^{\text {st }}$ heart sound in mitral area and mid diastolic murmur in mitral area.

Chest X-ray P/A view showed cardiomegaly, Electrocardiography showed atrial fibrilation. Echocardiography confirmed severe mitral stenosis with mild mitral regurgitation with AML and PML severely calcified and thickened, MVA $0.7 \mathrm{~cm} 2$, giant LA (70 mm) compressing RA, there was features of RV pressure and volume overload, spontaneous echo contrast seen in LA. Severe pulmonary hypertension, with a pulmonary artery systolic pressure estimated $118 \mathrm{~mm}$ of $\mathrm{Hg}$, Grade-III eccentric tricuspid regurgitation. With all aseptic precautions median sternotomy was done. Thymus dissected and ligated. Pericardiotomy was done and pericardial adhesiolysis was done. Cardio-pulmonary bypass was established with appropriate bicaval cannula. There was a $5 \times 4 \times 3 \mathrm{~cm}$ size organized LA thrombus was found (Fig-1) and thrombus was removed (Fig-2). Pulmonary veins opening were found free of thrombus. Mitral valve found both AML and PML thickened, severely calcified and moderate

Address of Correspondence: Prof. Md. Aftabuddin, Department of Cardiac Surgery, Bangabandhu Sheikh Mujib Medical University, Dhaka, Bangladesh. 

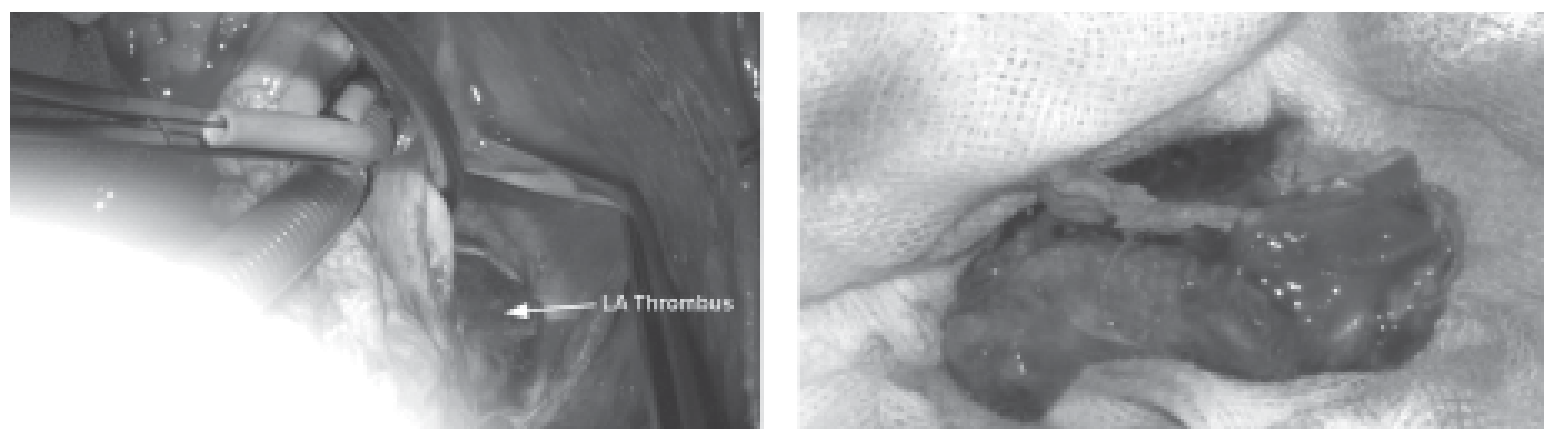

Fig.-1: Giant LA thrombus (Peroperative).

subvalvular change. All mitral valve apparatus excised and replaced with 27 size St. Jude porcine tissue valve. Left atriotomy was closed in layers. Two epicardial pacing wires were placed in RV wall. Chest closed in layers after keeping 3 chest drain tubes in situ; one in left pleural space, one in right pleural space and another in retrosternal space. Proper hemostasis was ensured. Per operative period was uneventful. Patient was extubated 3 days after operation due to low cardiac output syndrome. Chest drain tube removed on $11^{\text {th }}$ POD due to chest drain collection. Patient shifted from intensive care unit to ward on $12^{\text {th }}$ POD and discharged on $17^{\text {th }}$ post operative day.

\section{Discussion:}

According to Isomura and co-workers, left atria larger than $6 \mathrm{~cm}$ diameter is termed as giant left atria. ${ }^{5}$ In our patient had LA size was $70 \mathrm{~mm}$, which is consistent with the above study. Hurst states that in cases of giant left atrium, mitral regurgitation is more profound than mitral stenosis, and atrial fibrillation is almost always present. ${ }^{1}$ Most of the cases of giant left atria reported are associated with mitral regurgitation. In our case, X-ray chest of patient revealed cardiomegaly. On echocardiography, confirmed severe mitral stenosis with giant LA $(70 \mathrm{~mm})$ compressing RA. Giant left atria may rarely present in severe mitral stenosis. ${ }^{6}$ In our case it was associated with severe rheumatic mitral stenosis with AF, which is consistent with the above study. The patient of giant left atria usually presents with complaints of shortness of breath and/or dysphagia. ${ }^{7}$ Our patient had complaints of shortness of breath on exertion, palpitation without any compressive symptoms like dysphagia which is consistent with the above study. Such a giant left atrium with severe mitral stenosis with mild mitral regurgitation with $\mathrm{AF}$ is a rare entity, ${ }^{8}$ and hence we have reported this case. In the view of such enlarged left atrium with progression of symptoms with atrial fibrillation, we advised our patient for mitral valvular replacement surgery to avoid further complications. Successful mitral valve replacement surgery was done and patient discharged from hospital with advice.

\section{Conclusion:}

Patients of mitral valvular heart disease with severe mitral stenosis with mild mitral regurgitation may present with enlarged left atrium with progression of symptoms with atrial fibrilation and LA thrombus. Surgical management done successfully and patient discharged from hospital.

\section{Conflict of Interest - None.}

\section{References:}

1. Hurst W: Memories of patients with a giant left atrium. Circulation 2001; 104:2630-2631.

2. Plaschkes J, Broman JB, Mercin G, Milwidsky H. Giant left atrium in rheumatic heart disease: a report of 18 cases treated by mitral valve replacement. Annal of Surgery 1971; 174:194-201.

3. Kawazoe K, Beppu S, Takahara Y, Nakajima N, Tanaka K, Ichinashi K, Fujita T, Manabe H. Surgical treatment of giant left atrium combined with mitral valvular disease. Plication procedure for reduction of compression to the left ventricle, bronchus, and pulmonary parenchyma. Journal of Thoracic and Cardiovascular Surgery 1983; 85:885-892.

4. Tarun K, Deora S, Rajib A, Aggarwal A, Bhatt P, Manjunath CN. A giant left atrium: Largest left arrium reported from India. Journal of Medical Science \& Research 2012; 3: 28-29.

5. Isomura T, Hisatomi K, Hirano A. Left atrial plication. Journal of Cardiac Surgery 1993; 8: 365-370.

6. Agrawal AK, Gupta AK, Gupta VK, Kharb S. Giant Left Atrium: A Rare Entity in Rheumatic Valvular Heart Disease. Journal, Indian Academy of Clinical Medicine 2008; 9(3): 227-229.

7. Gould LA, Betzu R, Yang DC, Patel D. Giant Left Atrium- a case report. Angiology 1991; 42: 52-54.

8. Krishnamoorthy KM. 100\% Cardiothoracic Ratio. Texas Heart Institute Journal 2001; 28: 334-335. 